\title{
Editorial
}

\section{Financial Crises: Impact on Mental Health and Suggested Responses}

\author{
Nikos G. Christodoulou a George N. Christodoulou ${ }^{b}$ \\ ${ }^{a}$ Institute of Mental Health, University of Nottingham, Nottingham, UK; ${ }^{b}$ Department of Psychiatry, University of \\ Athens, Athens, Greece
}

\section{Introduction}

Financial crises are a reality that unavoidably affects mental health. Direct socioeconomic consequences like material disadvantage and inequalities, social fragmentation, unemployment, debt and worsened standards of living, as well as collateral consequences such as poor educational standards, can lead to poor mental health [1-4]. There is direct evidence from previous global financial crises as well as the present one linking these consequences to psychopathology, notably depression [5] and suicide [6]. The effects extend beyond personal and societal morbidity to systemic consequences that can affect mental health services, service delivery and policy. Ramifications are longitudinal and transgenerational, and therefore it is worth considering their management from a preventive viewpoint.

It is clear that mental health professionals need to make sense of the impact of financial crises on mental health and find appropriate, evidence-based responses to the challenges. This would be useful not only for already affected countries, but also for other countries at risk of suffering a 'contagion' effect. In this piece, we offer an evidence-based account of this topical issue and make response suggestions based on the experience gained from Greece as an example of a country severely affected by a financial crisis.

\section{KARGER}

(c) 2013 S. Karger AG, Basel

0033-3190/13/0825-0279\$38.00/0

E-Mail karger@karger.com

www.karger.com/pps

\section{The Effects of Financial Crises on Mental Health}

In her foreword to the World Health Organization booklet, Impact of Economic Crises on Mental Health [6], the World Health Organization regional director for Europe, Zsuzsanna Jakab, notes that the present economic crisis has led to a significant decline in economic activity, a rise in unemployment, depressed housing markets and an increased number of people living in poverty. This impact is currently worst felt in Greece, where unprecedented austerity measures have impoverished the population and caused a steep rise in unemployment, which is currently at $27 \%$ (November 2012), up from $7.9 \%$ in 2007 [7].

Socioeconomic decline can influence people's mental health through loss of jobs and limitations in income [8]. Unemployment, impoverishment and family disruptions are likely to produce or precipitate a variety of mental health problems, most prominently depression, suicide and alcoholism [6, 9-13]. An increase in the number of helpline phone calls with direct or indirect reference to the economic crisis has been reported in Greece. Most callers had depressive symptoms and were predominantly unemployed [14].

An increase in suicide attempts [15] and - arguably actual suicides $[16,17]$ has recently been reported in Greece as well as in other countries imposing austerity measures, such as Ireland [18] and England [19]. This

Dr. Nikos Christodoulou

Clinical Lecturer in Psychiatry, University of Nottingham

Room B08, Institute of Mental Health, University of Nottingham Innovation Park Jubilee Campus, Triumph Road, Nottingham NG7 2TU (UK)

E-Mail Nikos.Christodoulou@ nottingham.ac.uk 
evidence confirms earlier reports linking the financial downturn with increased suicide rates in European countries [20]. Unemployment is very strongly associated with suicide; every $1 \%$ increase in unemployment is associated with a $0.79 \%$ rise in suicides at ages younger than 65 years [21]. Unemployment may also be associated with increased homicide rates [22], which almost doubled in Greece between 2007 and 2009 [16].

Financial difficulties are associated with mental health problems, including suicide [23-26]. Even though debt per se is not necessary to precipitate mental illness [1], the more debt people have the more likely they are to suffer from mental disorders [26], while higher income may even be protective against suicide [22]. Also worth considering is that different types of financial problems tend to affect different population groups; for instance, high housing loan interest rates are associated with a higher incidence of suicide in younger people, but a lower incidence in the older population [23].

The association of psychopathology with poverty has been repeatedly demonstrated in culturally diverse cases and with consistency across time. Evidence from the Far East and Southeast Asia [27] indicates that severe financial losses due to the economic crisis of the 90s in Asia, and especially unemployment, resulted in suicide increases. The same holds for China, where the socioeconomic reforms of the last 3 decades were accompanied by a rise in suicides [28]. The mass suicides of farmers in India following the agricultural reform of the mid-90s are in line with the above [29].

It is particularly worrying that the socioeconomic determinants of a crisis can affect the development and mental health of children [30-32], and their effect may even persist in adult life [33], regardless of whether financial circumstances improve [1]. This transgenerational effect should alert not only health professionals but also society as a whole.

Cuts in public spending can effectively incapacitate public healthcare services, which in addition are expected to cope with an increased demand as impoverished people turn to the public sector for their healthcare. In Greece, public hospitals are currently struggling as they experience record attendances while their budgets have seen cuts as high as $40 \%$ [16]. The increased stress on the public sector is of ethical importance as it can lead to health inequalities, affecting the most vulnerable.

There is a well-documented relationship between socioeconomic determinants of financial crises and adverse physical health outcomes. This is perhaps best demonstrated by the link between unemployment and high mor- bidity/mortality rates [34, 35]. Recent evidence from Spain confirms a significant relationship between socioeconomic determinants and mental illness, including a rise in somatoform disorders [36], among others. On a similar trajectory alluding to the theory behind somatoform disorders [37, 38], Kentikelenis et al. [16] reported that in Greece people view their health as 'bad' or 'very bad'. The same study reports on increased heroin use and associated physical morbidity. Interestingly, contrary to evidence from other countries, a reduction in the overall consumption of alcohol since the beginning of the financial crisis was noted in Greece, coupled with a reduction in the number of drunk drivers [39].

\section{Responses to the Effects of Financial Crises}

\section{Differentiate Sadness from Clinical Depression}

The impact of the economic crisis on a societal level is typically described by the media as 'a depressed society', 'a depressed nation' and the like [40]. What the media are describing is sadness which is to one extent normal - a justifiable adaptive and even potentially productive response to an adverse, stressful life event. It is clinically important for mental health professionals to differentiate 'normal' sadness from clinical depression. Identifying a normal process as opposed to a pathological one may empower individuals, avoid stigma and prevent an unhelpful sick role from emerging. On the other hand, the threshold for diagnosing clinical depression should not be raised, but rather a formulation should emerge in which adaptive responses may explain part of clinical depression.

\section{Welfare Provision}

There is evidence that increased state welfare support can mitigate some of the mental health effects of financial crises. For instance, in the case of suicide, in Finland and Sweden - two states with advanced and well-funded social welfare systems - suicide rates did not increase and in some cases even decreased during economic hardship $[21,41,42]$. Conversely, reductions in state welfare spending in the USA were accompanied by increased suicide rates [43]. Similarly, a comparison of suicide rates during financial crises in Sweden and Spain from 1980 to 2005 revealed that suicide rates fell during Sweden's banking crisis in the early 1990s, while the reverse was observed in Spain following its banking crises in the 1970s and 1980s [21]. Sociocultural differences between Sweden and Spain may explain part of this observation, but resource allocation for social protection is certainly a major factor [6]. 
Corroborative evidence from Greece shows that suicide rates are inversely associated with the number of primary care, mental health service providers and the number of mental health infrastructures [44].

\section{Tackle Unemployment}

The link between indices of socioeconomic decline - particularly unemployment and poverty - and mental illness is complex and it is difficult to identify the direction of causality. Despite this, the strong association of unemployment with depression and suicide warrants the development of programmes to help people cope with unemployment or regain employment. Indeed, active labour market programmes may be able to counteract some of the detrimental effects of recessions on mental health [21]. Mental health professionals may have a role in promoting employment policies by communicating to policy makers the evidencebased returns for society, thus justifying the investment. The challenge here is to convince policy makers that this medium-term investment should take priority over short-term cost-saving measures and debt-servicing agendas.

\section{Tackle Inequality}

The important relationship between inequality and mental illness $[2,3,45]$ needs to be considered further in a psychiatric prevention context. If indeed the inequality gap contributes to the causation of mental illness, tackling the gap itself may be more beneficial than tackling its consequences. While tackling inequality is essentially a political task, it would still pertain to mental health and, therefore, we need to have the debate as to whether this task also lies within the remit of psychiatry $[3,46]$. Furthermore, there is a wider scope to tackling social injustice, as this can yield large health and social collateral gains [35].

\section{Culture-Specific Measures}

In its 2011 report, Impact of Economic Crises on Mental Health [6], the World Health Organization suggests action in five key areas for tackling the effects of economic crises on mental health:

- active labour market programmes

- family support programmes

- control of alcohol prices and availability

- primary care for the people at high risk of mental health problems

- debt relief programmes.

It is important to justify measures through global evidence but equally important to modify them to suit individual cultures so that they may reach their full potential [40]. For instance, while economic crises are linked to alcohol-related problems in some countries, in Greece the opposite effect has been observed, i.e. a reduction in alcohol consumption [16]. Therefore, alcohol-related measures may be a lesser priority in Greece.

Conversely, measures supporting institutions such as the family may be culturally more relevant in Greece [46] and possibly also in other Southern European countries. Recession in Southern European countries has resulted in more young people staying at their parental home due to their inability to maintain a separate household [47]. This is certainly negative developmentally as it discourages independence, but it may increase mental capital by supporting the extended family structure, strengthening generation ties and encouraging solidarity. Family support programmes can further enhance these positive 'side effects'.

The family's positive effect on mental health can be simulated through other culturally compatible ways. A good example is the 'foster families' scheme (a Greek scheme whereby chronic patients are housed with suitable and willing foster families) [48]. This programme has been piloted successfully by the Hellenic Centre for Mental Health and Research and the Athens University Department of Psychiatry. Such culturally compatible programmes may well prove to be effective and cost-effective, both directly and collaterally.

\section{Mental Illness Prevention and Mental Health \\ Promotion}

Mental illness prevention and mental health promotion are pivotal in mental health management $[46,49]$. Until recently, policy makers were reluctant to consider prevention in their policies because the evidence was scarce and benefits were longitudinal and too collateral to appreciate directly. However, recently there has been significant progress in building an evidence base on the effectiveness and cost-effectiveness of prevention and promotion [50], which has forced them in the agenda [51,52].

\section{Facilitate Resilience and Promote Positive Mental Health}

The emotional consequences of financial hardship must not be underestimated; loss can lead to withdrawal and depression, and anger can lead to aggression (towards others and oneself). While psychiatrists may not be able to give someone's job back, they may still help prevent psychopathology and even help people channel their negative emotions into something positive. As an example of this 'sublimation', in Greece some health professionals see the economic crisis as an opportunity to reform the healthcare system [53]. 
Psychiatry can actively facilitate resilience and support positive mental health through its role as the interface between medicine and the society. Through encouraging patient advocacy, it can empower people to be active participants in their own healthcare and the health service as a whole. Psychiatry can champion solidarity, altruism and social inclusion [54] and enhance social capital through promoting social networks [55]. Psychotherapy may also enhance resilience and well-being [56].

\section{Promote Investment in Mental Health}

There is ample evidence that mental health investments both work and save money [6,57-61]. Besides being effective and cost-effective, investment in mental health also benefits other sectors in society [62]. Furthermore, investing in the well-being of parents and their children can have long-term collateral as well as financial gains [63]. More generally speaking, investing in mental health contributes to cost-effectiveness and increased productivity in many ways and at many levels $[64,65]$.

Yet, investment in mental health has not always been proportionate to this evidence $[66,67]$. The reasons may be practical, as a considerable shift in services is required [57], but it is interesting that not only government officials but also the public view mental health as low priority when confronted with the need for budget cuts [68]. In view of the fact that in EU countries the economic impact of mental health problems is estimated to be equivalent to a reduction of $3-4 \%$ of the gross domestic product [69], giving mental health the priority it deserves acquires an additional strong reason - the economic one. Mental health professionals and advocates should communicate effectively these arguments to all stakeholders, including policy makers and the public. Among stakeholders, it is particularly important to support managers on the ground, as reform during a financial crisis can be particularly challenging.

\section{Continued Evolution of the Psychiatric Model}

Psychiatry is evolving from a nosocentric model to a more holistic, person-centred model. Various formulations of new models for psychiatry have supported the integration - beyond just the pharmacotherapeutic/biological dimension - of all different needs (bio-psychosocial, cultural, personal, etc.) to deliver individualised multidisciplinary care, including advanced psychosomatic and preventive considerations [70-74]. This broader approach has been endorsed by the World Federation for Mental Health, the International College of Psychosomatic Medicine and other organizations. It is becoming increasingly obvious that, especially in times of economic adversity, psychiatry cannot afford (both literally and existentially) to slow down its own evolution.

\section{Summary - Conclusions}

Economic crises are chronic stress situations and as such are likely to have psychological and psychopathological consequences. Indeed, they produce adaptive responses (normal sadness) and dysfunctional responses (mainly depression and suicidal potential). Managing the psychological consequences of financial crises is a complex undertaking, which may include political intervention. Diagnosing depression and suicide potential is important anyway but acquires greater importance during periods of economic crisis.

The financial crisis in Greece has adversely affected the physical and mental health of the population. Reports from Greece are particularly relevant because on the basis of them one may predict what is likely to happen in other countries ('contagion' of the mental health effects of the crisis), especially those with similar cultural and societal characteristics.

Unemployment, poverty and debt have been associated with psychiatric morbidity and suicide, and therefore measures to counter them may reduce harm. Welfare provision can limit psychiatric morbidity during periods of economic crisis, and active labour market programmes and family support programmes have been found to be effective and cost-effective. The measures to limit crisisprovoked morbidity should be culture specific.

Psychiatry can respond to the challenges posed by economic crises through its holistic, biopsychosocial and person-centred ethos. Important steps include promoting advocacy and empowerment on a personal level and solidarity and social cohesion on a societal level. Furthermore, mental health professionals can help enhance resilience and mental capital for those suffering from economic crises. Mental illness prevention and mental health promotion should be integral parts of clinical management and service planning in times of financial crisis. Mental health professionals should highlight the cost-effectiveness of mental health investments.

\section{Disclosure Statement}

The authors have no conflict of interest to declare. 


\section{References}

1 Laaksonen E, Martikainen P, Lahelma E, Lallukka T, Rahkonen O, Head J, Marmot M: Socioeconomic circumstances and common mental disorders among Finnish and British public sector employees: evidence from the Helsinki Health Study and the Whitehall II Study. Int J Epidemiol 2007;36:776-786.

$\checkmark 2$ De Vogli R, Gimeno D: Changes in income inequality and suicide rates after 'shock therapy': evidence from Eastern Europe. J Epidemiol Community Health 2009;63:956.

3 Pickett KE, Wilkinson RG: Inequality: an underacknowledged source of mental illness and distress. Br J Psychiatry 2010;197:426-428.

-4 Araya R, Lewis G, Rojas G, Fritsch R: Education and income: which is more important for mental health? J Epidemiol Community Health 2003;57:501-505.

$\checkmark 5$ Butterworth P, Rodgers B, Windsor TD: Financial hardship, socio-economic position and depression: results from the PATH Through Life Survey. Soc Sci Med 2009;69: 229-237.

6 World Health Organization: Impact of Economic Crises on Mental Health. Copenhagen, WHO Regional Office for Europe, 2011.

7 Hellenic Statistical Authority. www.statistics. gr (accessed February 2013).

8 Wilkinson R, Marmot M (eds): Social determinants of health: the solid facts, ed 2. Copenhagen, WHO Regional Office for Europe, 2003.

-9 Dooley D, Catalano R, Wilson G: Depression and unemployment: panel findings from the Epidemiologic Catchment Area study. Am J Community Psychol 1994;22:745-765.

10 Clark AE, Oswald AJ: Unhappiness and unemployment. Econ J 1994;104:648-659.

11 Dorling D: Unemployment and health. BMJ 2009;338:b829.

12 Lewis G, Sloggett A: Suicide, deprivation, and unemployment: record linkage study. BMJ 1998;317:1283-1286.

13 Agerbo E: Effect of psychiatric illness and labour market status on suicide: a healthy worker effect? J Epidemiol Community Health 2005;59:598-602.

- 14 Economou M, Peppou LE, Louki E, Komporozos A, Mellou A, Stefanis C: Depression telephone helpline: help seeking during the financial crisis (in Greek). Psychiatrike 2012; 23:17-28.

15 Economou M, Madianos M, Theleritis C, Peppou LE, Stefanis CN: Increased suicidality amid economic crisis in Greece. Lancet 2011; 378:1459.

16 Kentikelenis A, Karanikolos M, Papanicolas I, Basu S, McKee M, Stuckler D: Health effects of financial crisis: omens of a Greek tragedy. Lancet 2011;378:1457-1458.

-17 Fountoulakis KN, Grammatikopoulos IA, Koupidis SA, Siamouli M, Theodorakis PN: Health and the financial crisis in Greece. Lancet 2012;379:1001-1002.
18 Central Statistics Office Ireland: Report on Vital Statistics 2009. Dublin, CSO Office, 2012.

19 Barr B, Taylor-Robinson D, Scott-Samuel A, McKee M, Stuckler D: Suicides associated with the 2008-10 economic recession in England: time trend analysis. BMJ 2012;345: e5142.

20 Stuckler D, Basu S, Suhrcke M, Coutts A, McKee M: Effects of the 2008 recession on health: a first look at European data. Lancet 2011;378:124-125.

21 Stuckler D, Basu S, Suhrcke M, Coutts A, McKee M: The public health effect of economic crises and alternative policy responses in Europe: an empirical analysis. Lancet 2009; 374:315-323.

22 Giotakos O, Karabelas D, Kafkas A: Financial crisis and mental health in Greece (in Greek). Psychiatrike 2011;22:109-119.

23 Berk M, Dodd S, Henry M: The effect of macroeconomic variables on suicide. Psychol Med 2006;36:181-189.

24 Skapinakis P, Weich S, Lewis G, Singleton N, Araya R: Socio-economic position and common mental disorders. Longitudinal study in the general population in the UK. Br J Psychiatry 2006;189:109-117.

25 Brown S, Taylor K, Price SW: Debt and distress: evaluating the psychological cost of credit. J Econ Psychol 2005;26:642-663.

-26 Jenkins R, Bhugra D, Bebbington P, Brugha T, Farrell M, Coid J, Fryers T, Weich S, Singleton $\mathrm{N}$, Meltzer H: Debt, income and mental disorder in the general population. Psychol Med 2008;38:1485-1493.

27 Chang SS, Gunnell D, Sterne JA, Lu TH, Cheng AT: Was the economic crisis 19971998 responsible for rising suicide rates in East/Southeast Asia? A time-trend analysis for Japan, Hong Kong, South Korea, Taiwan, Singapore and Thailand. Soc Sci Med 2009; 68:1322-1331.

28 Phillips MR, Liu H, Zhang Y: Suicide and social change in China. Cult Med Psychiatry 1999;23:25-50.

29 Sundar M: Suicide in farmers in India. Br J Psychiatry 1999;175:585-586.

30 Anagnostopoulos D, Soumaki E: The impact of socio-economic crisis on mental health of children and adolescents. Psychiatrike 2012; 23:13-16.

31 Solantaus T, Leinonen J, Punamaki RL: Children's mental health in times of economic recession: replication and extension of the family economic stress model in Finland. Dev Psychol 2004;40:412-429.

32 Marmot MG, Bell R: How will the financial crisis affect health? BMJ 2009;338:b1314.

33 Paananen R, Gissler M: Cohort profile: the 1987 Finnish Birth Cohort. Int J Epidemiol 2012;41:941-945.

34 Brenner MH: Commentary: economic growth is the basis of mortality rate decline in the 20th century - experience of the United States 19012000. Int J Epidemiol 2005;34:1214-1221.
35 Marmot M, Allen J, Bell R, Bloomer E, Goldblatt P, Consortium for the European Review of Social Determinants of Health and the Health Divide: WHO European review of social determinants of health and the health divide. Lancet 2012;380:1011-1029.

36 Gili M, Roca M, Basu S, McKee M, Stuckler D: The mental health risks of economic crisis in Spain: evidence from primary care centres, 2006 and 2010. Eur J Public Health 2013;23: 103-108.

37 Kasl SV, Cobb S: Health behavior, illness behavior, and sick role behavior. I. Health and illness behavior. Arch Environ Health 1966; 12:246-266.

38 Kasl SV, Cobb S: Health behavior, illness behavior, and sick-role behavior. II. Sick-role behavior. Arch Environ Health 1966;12:531-541.

39 Hellastat Sector Study: Alcoholic Beverages. Athens, Hellastat, 2010.

40 Christodoulou NG, Christodoulou GN: Management of the psychosocial effects of economic crises. World Psychiatry 2013;12:178.

41 Ostamo A, Lönnqvist J: Attempted suicide rates and trends during a period of severe economic recession in Helsinki, 1989-1997. Soc Psychiatry Psychiatr Epidemiol 2001;36:354360.

42 Hintikka J, Saarinen PI, Viinamäki H: Suicide mortality in Finland during an economic cycle, 1985-1995. Scand J Public Health 1999; 27:85-88.

43 Zimmerman SL: States' spending for public welfare and their suicide rates, 1960 to 1995 : what is the problem? J Nerv Ment Dis 2002; 190:349-360

44 Giotakos O, Tsouvelas G, Kontaxakis V: Suicide rates and mental health services in Greece (in Greek). Psychiatrike 2012;23:29-38.

45 Kondo N, Subramanian SV, Kawachi I, Takeda Y, Yamagata Z: Economic recession and health inequalities in Japan: analysis with a national sample, 1986-2001. J Epidemiol Community Health 2008;62:869-875

46 Christodoulou NG and Anagnostopoulos DC: The financial crisis and the future of mental health in Greece. Int Psychiatry 2013; 10:3-6.

47 Eurostat: Youth in Europe: a statistical portrait. 2009 edition. DOI: $10.2785 / 30500$.

48 Tomaras V, Papageorgiou A, Soldatou M, Gournellis P, Christodoulou GN: Towards the rehabilitation of chronic mentally ill patients: a foster programme pilot (in Greek). Psychiatrike 2005;16:217-225.

49 Wahlbeck K, McDaid D: Actions to alleviate the mental health impact of the economic crisis. World Psychiatry 2012;11:139-145.

50 McDaid D, Zechmeister I, Kilian R, Medeiros H, Knapp M, Kennelly B, the WHEEN Group: Making the Economic Case for the Promotion of Mental Well-being and the Prevention of Mental Health Problems, WHEEN II Policy Briefing 3. London, Personal Social Services Research Unit, 2008. 
51 World Health Organization: Summary report: Prevention of Mental Disorders - Effective Interventions and Policy Options. Geneva, WHO, 2004.

52 European Parliament Resolution of 19 February 2009 on Mental Health. P6-TA-2009-0063. Available at http://www.europarl.europa.eu (accessed November 4, 2012).

53 Liaropoulos L: Greek economic crisis: not a tragedy for health. BMJ 2012;345:e7988.

54 Olié E: Social exclusion: the pathway from crisis to suicide oral presentation at the 2013 World Federation of Mental Health Congress 'Crises and Disasters: Psychosocial Consequences', Athens, Greece.

-55 Stuckler D, King L, McKee M: Mass privatisation and the post-communist mortality crisis: a cross-national analysis. Lancet 2009;373: 399-407.

-56 Fava GA, Tomba E: Increasing psychological well-being and resilience by psychotherapeutic methods. J Pers 2009;77:1903.

57 Vos T, Haby MM, Magnus A, Mihalopoulos C, Andrews G, Carter R: Assessing cost-effectiveness in mental health: helping policymakers prioritize and plan health services. Aust NZ J Psychiatry 2005;39:701-712.

58 World Health Organization: Dollars, DALYs and Decisions: Economic Aspects of the Mental Health System. Geneva, WHO, 2006. Available at: http://www who int/mental_ health/evidence/.
59 World Health Organization: Economic Aspects of the Mental Health System: Key Messages to Health Planners and Policy Makers. Geneva, WHO, 2006. Available at: http:// www who int/mental_health/evidence/.

60 Chisholm D, Saxena S: Cost effectiveness of strategies to combat neuropsychiatric conditions in sub-Saharan Africa and South East Asia: mathematical modelling study. BMJ 2012;344:e609.

61 Chisholm D, Sanderson K, Ayuso-Mateos JL, Saxena S: Reducing the global burden of depression: population-level analysis of intervention cost-effectiveness in 14 world regions. Br J Psychiatry 2004;184:393-403.

62 McDaid D, Knapp M: Black-skies planning? Prioritising mental health services in times of austerity. Br J Psychiatry 2010;196:423-424.

63 Mcdaid D, Park AL: Investing in mental health and well-being: findings from the DataPrev project. Health Promot Int 2011; 26(suppl 1):i108-i139.

64 Weehuizen R: Mental Capital. The Economic Significance of Mental Health. Maastricht, Universitaire Pers Maastricht, 2008.

65 Department of Health: No Health without Mental Health: a Cross-Government Mental Health Outcomes Strategy for People of All Ages. London, Department of Health, 2011.
66 Knapp M, et al (eds): Mental Health Policy and Practice across Europe. Buckingham, Open University Press, 2007.

67 Saxena S, et al: Resources for mental health: scarcity, inequity, and inefficiency. Lancet 2007;370:878-889.

68 Schomerus G, Matschinger H, Angermeyer MC: Preferences of the public regarding cutbacks in expenditure for patient care: are there indications of discrimination against those with mental disorders? Soc Psychiatry Psychiatr Epidemiol 2006;41:369-377.

69 Gabriel P, Liimatainen MR: Mental Health in the Workplace: Introduction. Geneva, International Labour Office, 2000.

70 Christodoulou GN: Psychosomatic Medicine. New York, Plenum, 1987.

71 Fava GA: A different medicine is possible. Psychother Psychosom 2006;75:1-3.

72 Fava GA: The decline of pharmaceutical psychiatry and the increasing role of psychological medicine. Psychother Psychosom 2009;78: 220-227.

73 Mezzich JE: Psychiatry for the person: articulating medicine's science and humanism. World Psychiatry 2007;6:65-67.

74 Mezzich JE, Christodoulou GN, Fulford KW: Introduction to the conceptual bases of psychiatry for the person. Int J Pers Cent Med 2011;1:121-124. 